\title{
Simple prediction model for unfavorable outcome in ischemic stroke after intravenous thrombolytic therapy
}

\author{
Modelo simples de predição de desfecho desfavorável em acidente vascular cerebral \\ isquêmico tratado após terapia trombolítica intravenosa \\ Daniel Amitrano 1,2, Ivan Rocha Ferreira da Silva',3, Bernardo B. Liberato ${ }^{1,3}$, Valéria Batistella', Janaina \\ Oliveira', Osvaldo J. M. Nascimento²
}

\begin{abstract}
Objective: We aimed to develop a model to predict unfavorable outcome in patients with acute ischemic stroke treated with intravenous thrombolytic therapy (IVT), based on simple variables present on admission. Methods: Retrospective analysis of acute ischemic stroke patients treated with IVT in a hospital in Rio de Janeiro. Clinical and radiographic variables were selected for analysis. Multivariate logistic regression was used to develop a predictive model. Results: We analyzed a total of 82 patients. Median National Institutes of Health Stroke Scale (NIHSS) on admission was 9 (3-22), 40.2\% presented with a hyperdense artery sign (HAS), 62\% had identifiable early parenchymal changes and $61.6 \%$ experienced a favorable outcome. An NIHSS score of $>12$ on arrival, age $>70$ and the presence of HAS were associated with the outcome, even after correction in a logistic regression model. Conclusion: An NIHSS $>12$ on arrival, presence of HAS and age > 70 years were predictors of unfavorable outcome at three months in patients with acute ischemic stroke treated with IVT.
\end{abstract}

Keywords: stroke; thrombolytic therapy; forecasting.

\section{RESUMO}

Objetivo: Desenvolver um modelo para predizer desfecho desfavorável em pacientes com acidente vascular cerebral isquêmico (AVCi) agudo tratados com terapia trombolítica intravenosa (TTI), baseado em variáveis simples presentes à admissão. Métodos: Análise retrospectiva de casos de AVCi tratados com TTI em um hospital no Rio de Janeiro. Variáveis clínicas e radiográficas foram selecionadas para análise. Foi utilizada regressão logística para desenvolver modelo preditivo. Resultados: 82 casos foram analisados. A mediana de escore de National Institutes of Health Stroke Scale (NIHSS) na admissão foi 9 (3-22), 40,2\% se apresentaram com sinal da artéria hiperdensa (SAH), 62\% possuíam alterações parenquimatosas precoces e 61,6\% obtiveram um desfecho favorável. NIHSS >12, idade > 70 e a presença de SAH foram associados com o desfecho, mesmo após correção em modelo de regressão logística. Conclusão: NIHSS > 12, a presença de SAH e idade maior que 70 anos foram preditores de desfecho desfavorável em 3 meses em pacientes com AVCi tratados com TTI.

Palavras-chave: acidente vascular cerebral; terapia trombolítica; previsões.

Stroke is one of the leading causes of morbidity and mortality worldwide, and since the approval of intravenous thrombolysis (IVT) with recombinant tissue plasminogen activator (rtPA, alteplase) in $1996^{1}$ as a treatment option, acute stroke management has experienced a paradigm shift. Focus has moved to prompt and accurate diagnosis followed by time-sensitive administration of a therapy that effectively and safely restores blood flow to the affected vascular territory.
Unfortunately, not all patients improve with IVT, and roughly $50 \%$ of treated patients will experience a favorable outcome (independence in activities of daily life and modified Rankin Scale score $0-2)^{2}$. Mechanical thrombectomy as an adjunct treatment has emerged as a rescue therapy for patients with proximal occlusion of major intracerebral arteries, but it is still not readily available in most countries. Hence, our objective was to identify simple and largely available clinical and

${ }^{1}$ Hospital Copa D’Or, Unidade de Cuidado Neurointensivo, Rio de Janeiro RJ, Brasil;

${ }^{2}$ Universidade Federal Fluminense, Departamento de Neurologia, Rio de Janeiro RJ, Brasil;

${ }^{3}$ Unidade Neurointensiva, Americas Medical Center, Rio de Janeiro, Brazil.

Correspondence: Daniel Amitrano; Hospital Copa D`Or, Unidade de Cuidado Neurointensivo; Rua Figueiredo Magalhães, 875 ; 22031 -011 Rio de Janeiro RJ, Brasil; E-mail: damitrano@gmail.com

Conflict of interest: There is no conflict of interest to declare.

Received 21 March 2016; Received in final form 06 July 2016; Accepted 24 August 2016. 
radiographic factors on arrival, which might aid in predicting the subset of patients who would experience an unfavorable response to IVT.

\section{METHODS}

\section{Study population}

Our study used an acute ischemic stroke databank from a Brazilian academic tertiary hospital, with prospective recruitment of 452 patients, admitted from January 2006 to October 2013. Entry criteria consisted of any patient treated solely with IVT. During this time frame, mechanical thrombectomy has not yet been fully studied and modern stent-retriever devices were not widely available in our institution. Upon first review, 103 patients who underwent chemical thrombolysis and/or mechanical thrombectomy were identified and, of those, 84 patients received only IVT and were selected for the study. Two patients who had posterior circulation strokes were excluded, as one of our variables of interest, the Alberta Stroke Program Early CT Score (ASPECTS), only applies to anterior circulation ischemic strokes.

\section{Variables of interest}

The following variables were selected for initial analysis: initial brain computed tomography (CT) findings, age, gender, severity of stroke upon arrival based on the National Institute of Health Stroke Scale (NIHSS) and functional outcomes at 90 days using the Modified Rankin Scale (mRs). We applied a previously-translated and validated NIHSS scale in Brazilian Portuguese ${ }^{3}$.

\section{Radiographic assessments}

Brain CT analyses consisted of searching for the presence of a hyperdense middle cerebral artery $\operatorname{sign}^{4}$ (HAS) and early parenchymal changes according to the ASPECTS ${ }^{5}$. Two stroke neurologists reviewed all scans independently, with $100 \%$ concordance.

\section{Clinical evaluation}

Certified stroke neurologists examined and recorded the NIHSS of all acute stroke patients as well as demographic and clinical variables. All outcomes were assessed at three months via telephone interview conducted by two stroke neurologists blinded to the remaining data. Unfavorable outcome was defined as mRS $>2$.

\section{Statistical analysis}

The association between the chosen variables and predefined outcome (mRs $>2$ at three months) was tested using the Pearson's Chi-Square and Fisher's exact test for categorical variables, $t$ test for normally-distributed continuous variables and the Mann-Whitney U test for non-parametric continuous variables, as well as univariate logistic regression analysis. Continuous ordinal variables were categorized as follows: NIHSS scores were dichotomized as greater than eight and greater than 12, based on previously-published data that correlated NIHSS $>8$ with unfavorable outcome 6 and NIHSS > 12 with major branch occlusion ${ }^{7}$; ASPECTS score was subdivided into values $\leq 7$ or $\geq 8$, since initial studies correlated cutoff values of $\leq 7$ for early parenchymal changes with unfavorable outcome after IVT ${ }^{8}$.

Age was also dichotomized in greater or less than 70 years, as a receiver operating characteristics curve developed with our data identified the age of 73 years as the cutoff point of greater accuracy for unfavorable outcome prediction (using Youden's index calculation). Moreover, previously-published data suggests that ages $>70$ might affect outcome after IVT ${ }^{9}$.

Multivariable logistic regression models were constructed to calculate adjusted odds ratios and risk ratios, as well as 95\% confidence intervals for the predictive effect of the multiple variables of the outcome. Candidate variables for the final multivariable model were tested in univariate logistic regression and step-forwarding models, and only variables with a $\mathrm{p}$ value $<0.05$ in univariate analysis were entered into the final model. All variables were independent, and no collinearity was detected. In the end, the Hosmer-Lemeshow test was performed to assess goodness-of-fit of the final model. Statistical analyses were conducted using SAS statistical software version 6.11 (SAS Institute, Inc., Cary, North Carolina). Statistical significance was set at $\mathrm{p}<0.05$ for the final logistic regression model.

\section{RESULTS}

Four hundred and fifty-two patients were initially screened, but only 82 cases fulfilled the criteria for the final analysis. Mean age was 76 (16-97) years and 47 (54\%) were female. Median NIHSS was 9 (3-22); 33 (40.2\%) presented with HAS; 49 (62\%) had identifiable early parenchymal changes (based on ASPECTS); and 45 (61.6\%) experienced a favorable outcome (mRs $\leq 2$ in 90 days). Door-to-needle median time was 43 minutes within the selected cases, as well as a symptoms-to-needle median time of 100 minutes and an incidence of symptomatic intracerebral hemorrhage after chemical thrombolysis of $1 \%$. Table 1 shows information on demographics at baseline and outcomes of the studied population.

After selection and testing of candidate variables with association metrics and univariate logistic regression, the only variables remaining with significant statistical correlation to the outcome were age $>70$, NIHSS $>12$ and presence of HAS (Table 2). All of the three variables remained statistically significant even after adjustment for competing effects in the final multivariate logistic regression model. Finally, a combination chart of predictive probabilities of unfavorable outcome based on the presence of risk factors on admission was created using logit analysis of the final model (Table 3). 
Table 1. Demographics at baseline and outcomes of the studied population.

\begin{tabular}{lc}
\hline Age & Mean: 76 years (16-97) \\
Gender & Female: 54\% (47) \\
& Hypertension: 71.8\% \\
& Diabetes: 28.2\% \\
& Tobacco use: 5\% \\
& Sedentary: 28.2\% \\
Risk Factors & Arrhythmia: $10,25 \%$ \\
& Dyslipidemia: $30.7 \%$ \\
& Previous stroke: 25.6\% \\
Skin Color & White: 79.4\% \\
\hline Mechanism of Stroke: & Large artery: $17 \%$ \\
& Small vessel disease: $5 \%$ \\
Outcomes at three months: & Cardioembolic: $18 \%$ \\
\hline
\end{tabular}

mRs: modified Rankin scale.

Table 2. Multiple logistic regression analysis: Independent predictors of unfavorable functional outcome.

\begin{tabular}{|c|c|c|c|}
\hline \multirow{2}{*}{ Variable } & \multicolumn{2}{|c|}{$\mathrm{p}$-value $(95 \% \mathrm{Cl})$} & \multirow{2}{*}{ Estimated OR } \\
\hline & Univariate & Multivariate & \\
\hline NIHSS > 12 & $<0.001$ & 0.0006 & $\begin{array}{c}19.4 \\
(3.54-106.7)\end{array}$ \\
\hline ASPECTS $<8$ & 0.015 & NS & - \\
\hline HAS & 0.001 & 0.049 & $\begin{array}{c}5.00 \\
(1.01-25.5)\end{array}$ \\
\hline $\begin{array}{l}\text { Age (without } \\
\text { dichotomization) }\end{array}$ & 0.002 & NS & - \\
\hline Age $>70$ & 0.002 & 0.004 & $\begin{array}{c}17.4 \\
(2.43-124.9)\end{array}$ \\
\hline
\end{tabular}

Cl: Confidence Interval; OR: odds ratio; NIHSS: National Institute of Health Stroke Scale; ASPECTS: Alberta stroke program early CT score; HAS: hyperdense artery sign; NS: not significant.

Table 3. Estimated probability of unfavorable outcome based on the presence of risk factors on admission.

\begin{tabular}{lccccc}
\hline Combinations & $\begin{array}{c}\text { Age } \\
>70\end{array}$ & $\begin{array}{c}\text { NIHSS } \\
>12\end{array}$ & HAS & $\begin{array}{c}\text { Estimated } \\
\text { probability } \\
(\%)\end{array}$ & $95 \% \mathrm{Cl}$ \\
\hline A & No & No & No & 1.6 & $0.2-11.2$ \\
\hline B & No & No & Yes & 7.6 & $1.0-40.1$ \\
\hline C & Yes & No & No & 22.2 & $10.7-40.4$ \\
D & No & Yes & No & 24.1 & $4.2-69.6$ \\
\hline E & Yes & No & Yes & 58.8 & $23.4-86.9$ \\
F & No & Yes & Yes & 61.4 & $17.6-92.2$ \\
\hline G & Yes & Yes & No & 84.7 & $51.8-96.6$ \\
\hline H & Yes & Yes & Yes & 96.5 & $78.3-99.5$ \\
\hline
\end{tabular}

NIHSS: National Institute of Health Stroke Scale; HAS: hyperdense artery sign; Cl: Confidence interval.

\section{DISCUSSION}

Intravenous thrombolysis is the standard therapy for acute ischemic stroke, as several studies have previously shown its safety and efficacy, even among elderly patients and in extended windows of treatment ${ }^{1}$. However, a significant subset of stroke patients may not experience the expected benefit, as only half of the patients achieve recanalization with $\mathrm{IVT}^{10}$. Also, roughly $50 \%$ of treated patients will experience a favorable outcome (independence in activities of daily life and mRS score $0-2)^{2}$. More recently, studies using mechanical thrombectomy as an adjunct treatment to IVT have reported impressive recanalization rates, leading to a much higher incidence of favorable outcomes when compared to therapy solely based on IVT ${ }^{11}$. Mechanical thrombectomy has emerged as an essential tool in comprehensive stroke centers, and might reflect the future of acute stroke therapy, but it is still not readily available in most countries ${ }^{12}$.

The current study showed that patients with a combination of age greater than 70, NIHSS greater than 12 and presence of HAS had a $96.5 \%$ chance of unfavorable prognosis. Hence, stroke neurologists might have an additional tool to screen for patients who might benefit from sequential therapies after alteplase, with no additional costs or delay of treatment, since in acute ischemic stroke, therapy response is extremely time dependent.

The association of prognostic markers with outcome has previously been studied in patients with acute ischemic stroke treated with IVT. The DRAGON score consists of tomographic findings, initial NIHSS, time to treatment, age, admission glucose and prior functional status ${ }^{2}$. The score has a reported accuracy of $86 \%$, with significant external validity. Despite its wide applicability, $44 \%$ of patients included in its original report had scores between five and six, a range with intermediate values of sensitivity and specificity.

The SVM score was developed in Europe using simple parameters, such as age, independence before stroke, normal Glasgow coma verbal score, ability to lift arms and to walk ${ }^{13}$. The SVM was similar in accuracy to the DRAGON score, but only for predicting a miserable outcome after IVT (mRs score 5-6 in three months).

Morerecently, the TURN score was developed, based solely on premorbid status (using mRs) and NIHSS on arrival, applying the orthogonalfunctionTURN $=-4.65+\left(\mathrm{mRS}^{*} 0.27\right)+(\mathrm{NIHSS} * 0.10)^{14}$. Subsequent studies have suggested that it might better predict 90-day outcomes when compared to DRAGON, as well as the occurrence of symptomatic intracerebral hemorrhage after IVT relative to some previously-published scores ${ }^{15}$. A major disadvantage is the cumbersome calculation involved and the initial design solely to predict symptomatic intracerebral hemorrhage after IVT.

The current study presents important limitations. First, without external validation, we cannot assure that the current data is applicable to other populations. Also, as the study 
entry criteria were strict, our cohort was not large enough to provide small confidence intervals. As a result, large confidence intervals were obtained due to lack of high statistical power, which limits the interpretation of the final regression model. Finally, our study has no data on long-term follow-up of the studied patients, which might create uncertainty about patients with delayed recoveries. In spite of that, one of the most striking strengths of our study is the fact that this is the first one on the prediction of outcomes after IVT using a South American population. Also, it is the first to provide calculated probabilities of outcome depending on multiple combinations of risk factors (Table 2).

The aim of this study was to identify patients who might not fully benefit from chemical thrombolysis alone, helping to select those who might need adjunct therapy. It might aid the practitioner as an early outcome predictor, but it could also serve as a hypothesis generator for future studies on chemical thrombolysis, as well as a possible screening tool for studies assessing mechanical thrombectomy as an adjunct to IVT. We strenuously oppose the use of this data to avoid offering intravenous alteplase to patients who might have unfavorable outcomes based on our findings. Intravenous thrombolysis is the gold standard therapy for acute ischemic stroke, and should be offered without exceptions to all eligible patients.

In conclusion, in the current study, the initial neurological exam with an NIHSS greater than 12, the presence of HAS and age greater than 70 years were reliable predictors of unfavorable outcome at three months in patients with acute ischemic stroke treated with chemical thrombolysis, even after correction in a multivariate logistic regression model. It might aid the practitioner as an early predictor of outcome. Moreover, it could serve as an hypothesis generator for future studies on chemical thrombolysis, as well as a possible screening tool for studies assessing mechanical thrombectomy as an adjunct therapy to IVT.

\section{References}

1. Jauch EC, Saver JL, Adams HP Jr, Bruno A, Connors JJ, Demaerschalk $\mathrm{BM}$ et al. Guidelines for the early management of patients with acute ischemic stroke: a guideline for healthcare professionals from the American Heart Association/American Stroke Association. Stroke. 2013;44(3):870-947. doi:10.1161/STR.0b013e318284056a

2. Strbian D, Meretoja A, Ahlhelm FJ, Pitkäniemi J, Lyrer P, Kaste M et al. Predicting outcome of IV thrombolysis-treated ischemic stroke patients: the DRAGON score. Neurology. 2012;78(6):427-32. doi:10.1212/WNL.0b013e318245d2a9

3. Cincura C, Pontes-Neto OM, Neville IS, Mendes HF, Menezes DF, Mariano DC et al. Validation of the National Institutes of Health Stroke Scale, modified Rankin Scale and Barthel Index in Brazil: the role of cultural adaptation and structured interviewing. Cerebrovasc Dis. 2009;27(2):119-22. doi:10.1159/000177918

4. Leys D, Pruvo JP, Godefroy O, Rondepierre P, Leclerc X. Prevalence and significance of hyperdense middle cerebral artery in acute stroke. Stroke. 1992;23(3):317-24. doi:10.1161/01.STR.23.3.317

5. Barber PA, Demchuk AM, Zhang J, Buchan AM. Validity and reliability of a quantitative computed tomography score in predicting outcome of hyperacute stroke before thrombolytic therapy. ASPECTS Study Group. Alberta Stroke Programme Early CT Score. Lancet. 2000;355(9216):1670-4. doi:10.1016/S0140-6736(00)02237-6

6. Sato S, Toyoda K, Uehara T, Toratani N, Yokota C, Moriwaki H et al. Baseline NIH Stroke Scale Score predicting outcome in anterior and posterior circulation strokes. Neurology. 2008;70(24 Pt 2):2371-7. doi:10.1212/01.wnl.0000304346.14354.0b

7. Fischer U, Arnold M, Nedeltchev K, Brekenfeld C, Ballinari P, Remonda $L$ et al. NIHSS score and arteriographic findings in acute ischemic stroke. Stroke. 2005;36(10):2121-5. doi:10.1161/01.STR.0000182099.04994.fc
8. Menon BK, Puetz V, Kochar P, Demchuk AM. ASPECTS and other neuroimaging scores in the triage and prediction of outcome in acute stroke patients. Neuroimaging Clin N Am. 2011;21(2):407-23. doi:10.1016/j.nic.2011.01.007

9. Dharmasaroja PA, Muengtaweepongsa S, Dharmasaroja P. Intravenous thrombolysis in Thai patients with acute ischemic stroke: role of aging. J Stroke Cerebrovasc Dis. 2013;22(3):227-31. doi:10.1016/j.jstrokecerebrovasdis.2011.08.001

10. Rha JH, Saver JL. The impact of recanalization on ischemic stroke outcome: a meta-analysis. Stroke. 2007;38(3):967-73. doi:10.1161/01.STR.0000258112.14918.24

11. Badhiwala JH, Nassiri F, Alhazzani W, Selim MH, Farrokhyar F, Spears J et al. Endovascular thrombectomy for acute ischemic stroke: a meta-analysis. JAMA. 2015;314(17):1832-43. doi:10.1001/jama.2015.13767

12. Evaristo EF. Endovascular thrombectomy in acute ischemic stroke: a major breakthrough and a big challenge for Brazil. Arq Neuropsiquiatr. 2016;74(1):1-2. doi:10.1590/0004-282X20150209

13. Seiffge DJ, Karagiannis A, Strbian D, Gensicke H, Peters N, Bonati LH et al. Simple variables predict miserable outcome after intravenous thrombolysis. Eur J Neurol. 2014;21(2):185-91. doi:10.1111/ene.12254

14. Asuzu D, Nyström K, Amin H, Schindler J, Wira C, Greer D et al. TURN: A Simple Predictor of Symptomatic Intracerebral Hemorrhage After IV Thrombolysis. Neurocrit Care. 2015;23(2):166-71. doi:10.1007/s12028-015-0131-z

15. Asuzu D, Nyström K, Schindler J, Wira C, Greer D, Halliday J et al. TURN Score Predicts 90-day Outcome in Acute Ischemic Stroke Patients After IV Thrombolysis. Neurocrit Care. 2015;23(2):172-8. doi:10.1007/s12028-015-0154-5 